International Journal of English Literature and Social Sciences
Vol-6, Issue-4; Jul-Aug, 2021

Peer-Reviewed Journal

\title{
From Subjectivity to Ineffability: Post-humanist Reflections on Pond
}

\author{
Sameh Tamin
}

Department of Intercultural Studies, ISSHT, Tunisia

Department of Linguistic, Literary and Aesthetic Studies, UIB, Norway

Received: 03 Jun 2021; Received in revised form: 21 Jun 2021; Accepted: 01 Jul 2021; Available online: 9 Jul 2021 (C)2021 The Author(s). Published by Infogain Publication. This is an open access article under the CC BY license (https://creativecommons.org/licenses/by/4.0/).

\begin{abstract}
Before the dawn of contemporary traditions, such as speculative fiction, literature and philosophy were predominantly anthropocentric. As, the utmost effort to dissect human existence did not wade further than rationalist endeavours at transcending the material self. Conversely, to counter-balance such anthropocentric and correlationist propensities, of excluding being to thinking, object-oriented ontologies resurfaced to redefine existential givens. In the seam of all this, branched by continental traditions, speculative realism and post-humanist art transpired in the hope of finding not just a middle ground that brings together both sides of contention, but a groundless space wherein subjects, objects and hopes for other enigmas defy the laws of definition, intelligibility and cognition. This paper will take on the debate surrounding subjectivity from the angle of contemporary fiction, chiefly among which, Claire Louise Bennett's Pond, all while going through theoretical commentaries on concepts such as consciousness, unconsciousness and subjectivity in an attempt to answer certain questions, essential to the ongoing issue.
\end{abstract}

Keywords - Stream of consciousness, Unconsciousness, Subjectivity, Posthumanism, Fragmentation.

\section{INTRODUCTION}

Pond is a collection of 20 short stories, written by Irish author, Claire Louise Bennett. It depicts fragments of the life of an unnamed woman, whom we can infer, but not ascertain, to be the protagonist of all the stories. In certain respects, Pond is different from the genre generally examined within Posthumanist scopes, namely; works whose plots rely on preternatural elements and which exhibit a certain extraterritoriality with the human reach. They do so through the disembodiment of human compositions, such as human cognition, and so often, the human body: a brain in a vat, a bodiless brain orbiting space, a brain without most of its processes, amnesiac personas, etc. In this line of plot, we mention Tom McCarthy's Remainder (2007), it too being about an unnamed narrator. Following an accident involving something falling from the sky, the narrator is left cognitively impaired. Upon receiving settlement money, he spends it on reenacting hardly remembered events from his past, which gradually turns to an unhinged thirst for violence and control. Another example is Joseph McElroy's Plus (2015). It is about Imp Plus, a disembodied brain controlling an Interplanetary Monitoring Platform that orbits the earth. Throughout the whole novel, we see Imp Plus's attempts to overcome his cognitive impairments, to wit, his struggle with memory, language, as well as his grasp of his own reality, all while progressively degenerating. Both novels rely on contorting the normative architecture of human reality by means of surreal plots. Pond, as will be elaborated further in this paper, does not rely on a phantasmagorical plot to evince its estrangement from normative human tendencies. In fact it doesn't rely on any plot at all. It rather depends on accounts of mundane elements of the protagonist's life in almost absolute seclusion, to create the same feeling of unfamiliarity with the human factor. In this respect Sara Maintland (2010), author of A Book of Silence describes 
Pond as "A very new sort of writing..." Where "... Bennett pushes the boundaries of the short story out into new territory: part prose, part stream of consciousness, often truly poetry and always an acute satisfying delicate, honest meditation on both the joys and frustrations of a life fully lived in solitude." This paper will, henceforth, reckon on Maintland's description to bring out what is most peculiar about Pond and show how these particularities converge with Posthuman appurtenances. The general aim is to dissect Pond and bring out all the scattered intents that Bennett might have never intended, in order to put a new perspective on her work and show how a book can still emit the same uncanny effect as works of sci-fi and speculative fiction without much imaginative extravagance and with only as fewer steps from reality as a work of fiction is entitled to. In this respect, we ask the following questions: How does Bennett exploit processes such as consciousness, unconsciousness and fragmentation to debunk the centrality of the self? In what way is Pond a post-humanist art? And what alternative do works such as Bennett's suggest to supplant subjectivity as a concept as well as a literary and an ontological priority?

\section{CONSCIOUSNESS, UNCONSCIOUSNESS, STREAM AND EQUIPOSE}

\subsection{Consciousness}

One can concurrently agree and disagree with Maintland's description. To say that Pond adopts the mode stream of consciousness is perhaps a setback for contemporary literature. But, since vagueness could easily be misconstrued as intersectionality, assessing the contemporary using modernist standards is often inevitable. This same broadness is what creates the controversy describing scholarly traditions such as postmodernism. Seeing as, it paradoxically adopts selfreferentiality simultaneously with the deconstructionist propensities of demolishing absolutes such as God, the intellect and the self. On that note, Deconstruction goes rather agreeably with current post-humanist objectives.

Otherwise, the term stream of consciousness was coined by American philosopher and psychologist William James (1890), who, in an attempt to illustrate the workings of such mode, defined it as follows.

"Consciousness, then, does not appear to itself chopped up in bits. Such words as "chain" or "train" do not describe it fitly as it presents itself in the first instance. It is nothing jointed; it flows. A "river" or a "stream" are the metaphors by which it is most naturally described. In talking of it hereafter, let us call it the stream of thought, of consciousness, or of subjective life." (p.239)
However, Pond is nothing if not "chopped up in bits", and is far beyond being a "train", perhaps, a train-wreck is more accurate, both equally haphazard and chaotic. Having said that, the reason why setting Pond forth as a stream of consciousness could be inaccurate, does not exclusively pertain to its lack of stream-like qualities, but mostly to the rarity of its conscious moments.

The omnipresence of the unconscious can be sensed in the occasionally unsubtle transitions from topic to topic: "The hopelessness of everything I was trying to occupy myself with was at last glaringly crystal clear. But the potato plants were still growing!" (Bennett, 2017, pp. 23-24). In this passage, just as the reader starts to think they are onto something important, an acquiring of at least one fragment of the narrator's person, or perhaps a sign of a small endeavour at some intimacy with the reader, their ambitions are brought into a halt by the potato plants which seem to be, by the sense of the shifted tone, many degrees more paramount than their predecessor, her thoughts. Perhaps it is precisely this one inclination of Bennett's, of throwing little hopes at some great divulgence that preserves the reader's interest in the stories despite the apparent lassitude and insipidity in its first impression. But it more surely looks like deliberate attempts at "unthinking" rather than a direct stream of thought, an inclination to emulate the brain's tendency to lose focus when focus is sought and to seek a fresh breath in mindlessness, irrelevance and uncertainty.

\subsection{Stream of Unconsciousness}

Daniel Dennett might have a different opinion on how consciousness, hence, a stream thereof might work. In his book Consciousness Explained, Dennett (1992) describes consciousness as a naturally discontinuous process:

"One of the most striking features of consciousness is its discontinuity - as revealed in the blind spot, and saccadic gaps, to take the simplest examples. The discontinuity of consciousness is striking because of the apparent continuity of consciousness. Neumann (1990) points out that consciousness may in general be a gappy phenomenon, and as long as the temporal edges of the gaps are not positively perceived, there will be no sense of the gappiness of the "stream" of consciousness." (p.356)

Does this mean that Maintland was right in classifying Pond as a stream of consciousness? Maybe. Does not being able to provide a definitive answer to this question indicate the futility of any attempt to confine Pond to one mode? Indeed.

\subsection{Meditative Equipoise: Between Loss and Control}

As a matter of fact, Pond seems to be an arena for something more peculiar than a cognitive affiliation. 
Rather, it exhibits a natural unfolding of the human mind between consciousness and unconsciousness, without a third party, not even the self, something like meditation?

In point of fact, Sara Maintland, too, happens to think that Pond is very much like meditation. Similarly, in Unthought, Katherine Hayles (2017) explains how meditation attenuates the exhaustively over-conscious presence of the self:

"The obvious conclusion is that there is no self as such, only the transient flow of experience. Because consciousness fears that the loss of selfhood would equal death, it tends to panic and to grasp after the illusion of a self. The purpose of meditation is to overcome this reaction, realize the absence of a self (emptiness or sunyata) as an opening out into the world instead of a loss, and begin to explore the experience of awareness within this opening out." (p. 62)

By a similar token, one might also look at this meditative inclination as an oscillation between subjectivism and objectivism, and a surpassing of both. In the aftermath of the above-mentioned, Hayles refers to the Buddhist traditions of Madhyamika schools and how, they seek "a 'middle way' between objectivism and subjectivism, through reducing every entity, from subject to object, all equally, to an unessential emptiness. Such realization is often achieved through meditative equipoise.

On the subject of fearing the "loss of selfhood", Pond exhibits a general disregard for control, sarcastically insinuated in one of the stories "Control Knobs". But, as is so often the case during meditation, you also find an interplay between yielding and unyielding to the "loss of selfhood". The tendency to "panic", as well as the need for a "grasp" is especially found in "Finishing Touch".

Much like McCarthy's Remainder, the narrator in "Finishing Touch", who in the simple act of planning and hosting a house party, manages to display a compulsive need to control everything down to who ought to sit on the ottoman. In fact, she shows a nearly obsessive interest in the ottoman, so much that the ottoman can safely be considered the focal point of this one story.

This collection of stories that got us so confused with its twisted sense of priority, where bananas, oatcakes and black jams are equally as important as the narrator's love life or childhood memories, hardly showed evidence of having a focal point or a definitive aim. This invites two congruent interpretations.

The first entails that the ottoman, an object, and the importance allotted to it, is used to encourage the shift of centrality from subject to object, ergo, from subjectivity to objectivity. The second interpretation is that the ottoman might also be emphasized in order to depict how compulsive control, which largely characterizes conscious thought, is contingent upon having a centre, an aim, a bull's eye, an "ottoman".

"Thought encompasses an "aim-oriented flow of ideas and associations that can lead to a reality-oriented conclusion" (Marić, 1982, p. 22)

In other words, what is thought, as opposed to what is "unthought", is defined by a directed need for control in order to reach a certain conclusion which is mainly the aim of the thought process. In narratives adopting the stream of consciousness, it generally pertains to an ultimate search for "selfhood" and "individuation". In works such a Pond and Remainder, controlling and aim- oriented processes are depicted pejoratively, as a defect, or a hindrance to the whole cognitive system.

However, conversely, Pond as a whole does not epitomize the active flow of pondering, present in the stream of consciousness, it is not stream-like, but rather interrupted and motionless. One might even say it is pond-like, and more generally a collection of dispersed ponds, different in size, made of the same water, yet still disconnected, by means of irrelevance, aimlessness and intentional absurdness. By way of example, let's consider this, comparatively, quite short story.

“Oh, Tomato Puree!

Oh, Tomato Puree! When at last you occur to me it is as something profuse, fresh, and erupting. Alas, when I open the door and reach for you, the chill light comes on and shows you crumpled, cold, and, despite being well within your sell-by-date, in dire need of coaxing. Oh, Tomato Puree-let me lay you out and pummel those rigid furrows and creases! Reconnecting your fractured substance, so you might push aside the residue of previous abundance and come forth again, in all your kitsch and concentrated splendour." (Bennett, 2017, p. 117)

At a first glance this short story seems to be an independent pause that seeks to display a certain penchant towards the marvel that is tomato purée. After a couple of more glances it still looks like an irrelevant tribute to tomato purée. However, the last sentence in this small fragment of Pond, could be as crucial to our ongoing point as it is to the purée. First, whether intentionally or not, the idea of "Reconnecting your fractured substance", sums up the whole spirit of Pond as a collection of fractured substances or as previously put, dispersed ponds of the same water, same substance, however fragmented and disconnected it is.

Is it legitimate to consider moments such as these, which happen to be pervasive, as meta-textual self-commentaries 
that propound the book's stylistic choices as well as ideas? If so, could irrelevance conversely be the very element that Bennett uses to isolate and call attention to these metatextual instances? More importantly, granted it is indeed a meta-textual instance, should this reference to one of the major tools of post-humanist art, namely disembodiment, also present in Pond, be considered Bennett's testament to the Post-human nature of her book?

\section{SUBJECTIVITY AND THE EQUATION OF IMPORTANCE}

\subsection{Neglected Intersubjectivities}

First of all, it is not sure whether one should look for embedded meanings or insinuations in Pond. In fact, in "The Big Day", the reader's efforts to look for an implicit meaning for the term "pond" is discouraged, "She must have made me a cup of tea anyhow, before she went off to place a cautionary notice next to the pond - which, by the way, has absolutely no depth whatsoever." (Bennett, 2017, p. 40) Perhaps this too was not meant to mean anything other than what it was supposed to mean. However, contradictorily, if this extract is to be considered a deterrent, then, it should automatically denote a metatextual pause. Nevertheless, Bennett's objective, if objective were to be, seems to aim at losing meaning rather than gathering it from what otherwise looks like scattered hints that seduce and invite the scavenger in every reader then reject them at the same time, which makes it a Post-human work par excellence.

On the whole, Claire Louise Bennett does not seem too keen on establishing a relationship between herself and the reader. She keeps her distance, by teasing, stalling and pervasively using the phrase "If you must know." It is as if her intention is hindering the forming of that bond, that intersubjectivity which allows the reader to absorb whatever the author is projecting, enabling the creation of a network of conversations between multiple two selves, where the author is inherently at the other end and at the centre. Nevertheless, the reader still gets a taste of Bennett the seductress, in her little attempts to stall, tease, connect then deliberately lose the reader. This is reminiscent of, or even embodied by, the protagonist of Pond herself. Her way of flirting is similar to how Bennett (2017), herself, flirts with her readers.

"Weeks, in fact, where I spent time with a man, sometimes in a state of inebriation, sometimes in a condition of sobriety, and, when I reflected upon this period of time, I had little option but to posit that, overall, relations with the man in question fared significantly better when I'd imbibed a little alcohol.” (p. 56)
Similarly:

"And yet, how to reconcile such a fortunate and encouraging record with the aforementioned assertion that I was, in the most part, quite unable to endure advances made by any one of these extraordinary men until I had achieved a precise tone of inebriety?" (p. 58)

\subsection{Inebriety, Importance, and Tempered Priorities}

One can sense a ubiquitous inebriety in Pond, which is as elemental for the loss of control and selfhood in general, as it is in this collection of stories. This recurrent commute between instances of inebriety and sobriety makes the conversion from "critical indifference" and passivity to "mindless fascination" (Bennett, 2017, p. 58), rather pervasive and confusing. Such gratuitous fascination allows every element in Pond, a chance at momentary importance. This comes directly opposite to the general unimportance promoted by the Buddhist traditions of Madhyamika schools, which in a way amounts to an identical difference; a blank page could be perceived as a page entirely filled with condensed white dots, or whatever colour one attributes to blankness. In other words, if all the elements in a story are equally as important, then no element is really important.

Equivalently, this gives Bennett an excuse to further temper with the reader's sense of priority, as potatoes and tomato purées, somehow, become as fascinating to the reader as they are made to be. And in a way the reader, too, is taken from critical readiness, to critical indifference, to a mindless fascination that awakens an unfamiliar awareness which revives their resigned critical self, only to inhibit it yet again by the overwhelming indifference of the due subsequence. This flirtatious journey makes it that the readers are neither able to pull their attention nor to ever reach a climax. Consequently, they are stuck in a middle space, or an extra dimension that Bennett creates. Such zone seems to be her very target to begin with, a loss of selfhood in a new space where it is not the centre, another posthuman propensity.

However, it also betrays Bennett's disregard for the readers' selfhood by treating them as premature individuations with her fake promises of connection. Needless to say, that if Pond does not allow space for selfhood and subjectivity, it is only natural to disallow intersubjectivity the same privilege.

Inebriety is also primordial in the fact that it inhibits active reflections and conscious thought processes. "Something that prevents one from scrutinising and dissecting everything that is said; something that shuts off the mounting dismay and stumbling evasions; something that enables me to hang off every word." (Bennett, 2017, p. 58) 


\section{POSTHUMANIST MODES: DENUATING THE HUMAN FACTOR}

\section{1 .Unnaming, Unlearning}

Bennett's relationship with words recurs on multiple occasions. One of the short stories is entitled "Words Escape Me". In her other story, "The Deepest Sea", the narrator exhibits a state of unfamiliarity with a word, "....and one of the first words he used in his description was a term I did not really know the meaning of..." (114). "The Big Day", is where she figuratively disavows English as her first language, "English, strictly speaking, is not my first language by the way. I haven't yet discovered what my first language is so for the time being I use English words in order to say things." (44). Similarly, in both McCarthy's Remainder, and especially in McEleroy's Plus, there is a recurrent display of unfamiliarity and estrangement with words, "The words were not much inclined." (McEleroy, 17).

Primarily, in both novels, this amnesiac inclination as regards to words seems as a natural consequence to both events. Both plots rely on the absence of unconscious processes such as memory and language which work in the back ground, invisible to our awareness. The absence of these processes eventually proves destructive to both protagonists, which lays bare an impotence of the very consciousness that we think so omnipotent, and that we often mistakenly call the self:" "unthought' may also be taken to refer to recent discoveries in neuroscience confirming the existence of nonconscious cognitive processes inaccessible to conscious introspection but nevertheless essential for consciousness to function." (Hayles, 2017, p. 1)

However, this ostentatious emphasis on unfamiliarity with words and language is meant to mirror a Post-human propensity for unlearning. In the same context Hayles (2017) refers to "the Zen- like cult of the Handdarata and their tradition of "unlearning" (p. 1) This technique is yet again, an anti-anthropocentric way to debunk the centrality of humans and their pre-established symbols. At last, we should not forget to address the elephant in the room; the protagonist of Pond remains to the very end without a name, which further reinforces the lack of resolution and definition that had, since the beginning, described Pond.

\subsection{Fragmentation:}

Another literary technique meant for the deconstruction of pre-established foci is fragmentation, or disembodiment, incessantly found in Pond. Events, memories and details about the narrator's life are presented in fragments.

Actually, fragmentation is a Post-modern trend. However, "Le Nouveau Roman" genre, which typically falls into contemporary literature, is most known for its use of this devise. The new novel theory was put forward by Alain Robe Grillet (1963) in his collection of essays Pour un Nouveau Roman. It meant to break with the established writing norms, concerning plot, narrative, and especially characterization.

One of the main objectives of this new mode, mainly enabled through fragmentation, is the depersonalizing of the narrative, which brings back the issue of subjectivity. In this point specifically, Pond can justly be defined as post-humanist art in its tendency to deny the singularity of the human identity by highlighting the epiphenomenal nature of consciousness, all through fragmentation, discontinuity, as well as gaps within both form and content.

\subsection{Isolation}

On another note, we address this one last sentence in Maintland's (2010) critique:

"...honest meditation on both the joys and frustrations of a life fully lived in solitude."

Pond most certainly exhibits an almost uncanny sense of seclusion. It is after all a story about a woman who chose a solitary cottage life in a small village on what appears to be the west coast of Ireland. What is most peculiar, however, is that this unsettling solitude comes in the form of echoes throughout the whole collection. Bennet gives voice to every element surrounding the narrator, so much so it ends up emphasising the lack of human presence in the stories.

Generally, in a secluded setting, the quietude allows every noise to be emitted in the form of an echo, thus permitting the noises let out by our nonhuman surroundings, which in the otherwise abundance of human presence are indiscernible, to become vociferous. Inversely, by dint of the over-amplified background sounds in Pond, Bennett (2017) allows an implicit feeling of solitude to echo:

"Within these deep stone walls the sound of a large knife pounding against the chopping board is often mellow and euphonious; like a lolling chant it charms and placates me.” (p. 32)

\section{THE POSTHUMAN ALTERNATIVE}

\subsection{Green Fiction}

Natural elements become characters in Pond. In fact, they are given voice and made prominent, from "beech trees" down to the "small beetle".

"I would listen to the small beetle skirting the hairline across my forehead. I would listen to a spider coming through the grass towards the blanket. I'd listen to a 
squabbling pair of blue tits seesawing behind me. I'd listen to the wood-pigeon's wings whack through the middle branches of an ivy-clad beech tree and the starlings on the wires overhead, and the seagulls and swifts much higher still. And each sound was a rung that took me further upwards, and in this way it was possible for me to get up really high, to climb up past the clouds, towards a bird-like exuberance, where there is nothing at all but the continuous light and acres of blue. Later on towards evening, as it got cooler, I would snuggle into myself a little more and listen less and less so that, very slowly, I returned to dusk and earth.” (Bennett, 2017, pp. 31-32)

This passage is specifically congruent with Hayles's (2017) description of meditation "as an opening out into the world instead of a loss" as we "begin to explore the experience of awareness within this opening out." (p. 62). The idea of awareness is also redolent of Pond, its unduly focus on details reflects an even more inordinate tendency to be aware of every surrounding item, material force, or as Hayles would put it, non-cognizer.

In both passages Hayles and Bennet, whether deliberately or not, show a Post-human inclination to subvert the humanist devoir towards embodiment and subjectivity, by taking the human cognition out of its physical container and propelling it onto the world, "further upward". By removing corporeality from human factors, they allow for the imagination of a new order, a new eco-system, not for humans and non-humans, but rather cognizers and noncognizers, hence exploring the idea of a cognitive ecosphere, where the human self is by no means central.

The same idea is elemental in Joseph McElroy's Plus, or in the "Brain in the Vat" scenario, where disembodiment is the crux of the whole scheme. What these works have more in common is the idea of a "remainder", a "plus", even the "pond" can be considered a desolate remainder of the outpouring of rain, but what does everything above imply?

In the framework of the interplay between consciousness and unconsciousness, and by means of ridding the conscious of its unconscious processes, the aforementioned works seem to aim at proving that despite the common idea about consciousness being the most vital part of human cognition, without its unconscious counterparts, it is nothing more than a remainder or a plus. The same goes for the self, which is generally correlated to consciousness, because of its supposed higher position. In this respect Bennett (2017) uses the word remainder as follows:

"... -in fact there should be a definite remainder of green along the stalk, and if there isn't, forget about it.” (p. 15)
The colour green mentioned in this excerpt is pervasively referred to in Pond as it is in Plus. "The green thing did not have eyes. Imp Plus had thought of its eyes, but he had not really seen the green thing. Yet he had seen green. Was he in error?" (McElroy, 2015, p. 34) Is this a prospective attempt at rewriting the future in green ink, through green fiction, an ecological re-imagination, where nature is as important as Man?

If so, this would only prove that these are Post-human works of fiction par excellence. And if Bennett (2017) was openly trying to divulge her inclinations, she wouldn't find a better way to say it than as follows: "This is being written with green ink-though in fact it is not, not yet." (p. 103)

\subsection{The New Planetary Order}

What remains in question is the alternative to an overriding rationality and an over-conscious subjectivity that supposedly give Man precedence over all worldly elements. From what I've gathered throughout this research, an alternative focus is void, most fit to illustrate the goals put forward by the Post-human tradition, that of non-centrality, undefinition and ineffability. Void is shapeless and undelineated, it cannot hold a center, because « centers must hold». Essentially, for void to be, existence has to cease, Man has to cease. As a matter of fact, for mankind centrality has been an ontological hinge, crucial for human perpetuity and survival. But since humanity entered what is unofficially perceived as the Anthropocene, this centrality has become a contingency. And a change of order has become an ontological hinge for humans especially. Therefore, when we speak about void in action, we speak about the death of Man, hence why, Posthumanism is apocalyptic in many regards. And since the breakthrough of technology and technological possibilities, the idea of demolishing the human subject has become sharply outlined. Truthfully, Alexa or any AI personification render the «autonomous rationality» discourse rather ridiculous. However, in practical terms, we talk about a theoretical void, in the sense of expunging pre-established human terms to enable the creation of a new planetary order of equal ecosystems. In this respect, we talk about Critical Posthumanism, in its radical reworking of humanist inclinations. It would be done by means of unlearning and unnaming the factors that made humanity central, for the new planetary ecology to be all inclusive, chiefly among which is language. In fact, in an interview with the Laureate for Irish Fiction, Sebastian Barry, who hosts a series of brief conversations with fellow writers, namely "What the Hell/Heaven Are We Doing?", Claire- Louise Bennett (2017) dwells on her relationship with writing. She asserts: "It means to kind of knock on the instruments of words to create some kind of a 
pathway; that's my relationship to language, it has the ability to bring you into proximity with the ineffable." Perhaps enough to become the ineffable.

\section{CONCLUSION}

Plot-wise, Pond is an honest rendition of real life human factors. It does not contain elements suggesting imaginative exaggeration. On the contrary, it is well congested in details about everything that surrounds a reality-based self, so much so it rids them from their function as peripherals. In a sense, Pond bares subjectivity from its centrality by ridding peripheral components of their marginality. However, what Bennett really adds to the Post-humanist platform is the matter of isolation. In fact, isolation is elemental to the anthropocentric construct. Isolation, distinction and separation are at the base of speciesism or any form of segregation for that matter. However, through making seclusion its predominant theme, Pond manages to use it as its primary substance in reversing the centrality of subjectivity. Bennett isolates one self, deconstructs it into fragments, or short stories, that lose their omnipotence within the echo of the rest of the ingredients. Consequently, through her narrative, Claire Louise Bennett manages to create a prototype of the new order previously presented in this paper, an ecosphere of co-existing constituents of equal importance, among which subjectivity co-lives. Fiction, such as Pond, Plus or Remainder, seem to promote Post-humanist objectives through stylistic features such as fragmentation, irrelevance and the occasional roaming about emptiness. Furthermore, they create alternative spaces where irrationality, unreason and even madness are not peripheral or hindering to the world but elemental to it. The intertextual endeavours, attempted by this paper permitted us to extract the main point of intersection, primarily, between such works, and inherently with the Post-humanist tradition, namely the rejection of a central subjectivity. Works, like Katherine Hayles' Unthought, provide a theoretical counterpart to these literary propensities through examining the vicinities of selfhood and subjectivity within cognitive sciences. Moreover, they help explore the innerworkings of key concepts such consciousness and unconsciousness. Ultimately, both fiction and theory intersect at the same end, that is, the importance of unlearning, undefinition and ineffability for the prospective reimagining and recreation of a decentred ecosphere. What this paper intended to add to the critical table is the possibility of examining works such as Bennett's, which rely on the «slice of life» approach rather than imaginative and futuristic concepts, through a Post-humanist lens. Although, Post-humanism is well established as a critical discourse within humanities and social sciences, it hardly permeates to non-speculative fiction. The scarcity of such models was not just the primary incentive behind this paper, but also it's first challenge. This project was written in the hope of evincing the possibility of such reading and of similar ones to be rendered on works proverbially belonging to other cultural trends, such as Modernism or Postmodernism. This prompts us to ask, where do we really draw the line between literary movements? Is there even a line to begin with?

\section{REFERENCES}

[1] Bennett, C. (2017). Pond (Reprint ed.). Riverhead Books.

[2] Dennett, D. C. (1992). Consciousness Explained (1st ed.). Back Bay Books.

[3] Grillet, A. R. (1963). Pour un Nouveau Roman. Les Editions de Minuit.

[4] Hayles, K. N. (2017). Unthought: The Power of the Cognitive Nonconscious (Illustrated ed.). University of Chicago Press.

[5] James, W. (1890). The Principles Of Psychology. Henry Holt \& Company.

[6] Maitland, S. (2010). A Book of Silence (Reprint ed.). Counterpoint.

[7] Marić, J. (1982). Klinicka psihijatrija sa okupaciono-radnom terapijom u psihijatriji. Visa medicinska skola.

[8] McCarthy, T. (2007). Remainder. Vintage.

[9] McElroy, J. (2015). Plus. Dzanc Books.

[10] Nayar, P. K. (2013). Posthumanism (1st ed.). Polity.

[11] Punday, D. (2018). Algorithm, Thought, and the Humanities: A Review of Unthought: The Power of the Cognitive Nonconscious. Electronic Book Review. Published.

[12] Widewalls Editorial. (2016, October 6). Posthumanism and Contemporary Art. Widewalls. https://www.widewalls.ch/magazine/posthumanismcontemporary-art 